\title{
Peripheral Nerve Stimulation of the Thoracic Paravertebral Plexus for Chronic Neuropathic Pain
}

Dominic Hegarty, MB, FCA RSCl, and Teodor Goroszeniuk, MB, FRCA

From: Department of

Pain Management and Neuromodulation Centre, Guys and St Thomas' NHS Foundation

Trust, London, UK

Dr. Hegarty is Clinical Fellow Pain Management, Department

of Pain Management and Neuromodulation Centre, Guys and St Thomas' NHS Foundation

Trust, London SE1 7EH, UK

Dr. Goroszeniuk is Consultant,

Department of Pain Management and Neuromodulation Centre,

Guys and St Thomas' NHS

Foundation Trust, London, UK

Address correspondence: Dr. Dominic Hegarty Department of Pain Management and Neuromodulation Centre,

Guys and St Thomas' NHS

Foundation Trust, London SE1 ${ }_{7} \mathrm{EH}$, UK

E-mail: dominichegarty@hotmail. com

Disclaimer: There was no external funding in the preparation of this manuscript.

Conflict of interest: None.

Manuscript received: 11/07/2010

Revised manuscript received: 01/03/2011

Accepted for publication: 04/04/2011

Free full manuscript: www.painphysicianjournal.com
Persistent post surgical pain is reported in $70 \%$ of patients following thoracotomy and mastectomy. This pain is often neuropathic in nature and occasionally it is refractory to traditional medical and interventional management. Neurostimulation of peripheral nerves can be a highly effective clinical modality for the management of neuropathic pain. The placement of a percutaneously sited electrode in the thoracic paravertebral plexus offers a new and novel mode of managing refractory thoracic neuropathic pain.

We present 2 cases that demonstrate the effectiveness of this intervention in the long-term management of this clinical dilemma. The first case presented is that of a 61-year-old female, with unilateral neuropathic pain for 6 years following mastectomy refractory to traditional interventions. Targeted field stimulation of the thoracic paravertebral plexus resulted in significant improvement for 12 years. The second case is that of a 65-year-old male, with Type II diabetes with neuropathic thoracic pain for 6 years following multiple rib fractures (T4-T7) who responded positively to neurostimulation of the thoracic paravertebral plexus.

Both of these cases demonstrate a relative reduction in pain intensity $(>80 \%)$, the elimination of oral analgesics, and improved functionality directly related to the novel use of this intervention. Effective and reproducible pain relief is achieved by specifically using a low frequency $(10 \mathrm{~Hz})$ and low amplitude ( $2 \mathrm{~mA}$ ) stimulation technique. Equally important is that these cases highlight the increased risk of inadvertent pleural puncture with the development of a pneumothorax that can be associated with this intervention. Possible clinical, investigative and equipment modifications that need to be considered are discussed.

The limitations include only 2 case reports, considered as the lowest level of evidence available in the era of evidence-based medicine, and lack of utilization of multiple other modalities of treatments utilized in managing neuropathic pain.

In conclusion, these cases demonstrate the effectiveness of peripheral nerve stimulation of the thoracic paravertebral plexus in the long-term management of refractory neuropathic pain. They also serve to underline the importance of clinical awareness in order to improve patient safety.

Key words: Peripheral nerve stimulation, thoracic paravertebral plexus, persistent post surgical pain, neuropathic pain, pneumothorax

Pain Physician 2011; 14:295-300
D ersistent post surgical pain is reported in $70 \%$ of patients 2 months following thoracotomy and mastectomy surgery. Thoracic paravertebral blocks have been shown to be useful to relieve acute postoperative pain associated with this surgery (1), but long-term pain relief is variable $(2,3)$. Peripheral nerve stimulation (PNS) is a neuromodulation technique with important therapeutic and cost-effective benefits, especially for neuropathic pain previously refractory to conventional treatment modalities (4-9). 
We present 2 cases, with long-term follow-up, using PNS of the thoracic paravertebral plexus for chronic thoracic pain of different etiologies which failed to respond to conventional treatments. We also highlight complications associated with this treatment.

\section{Case Reports}

\section{Case 1}

In 1998 a 61-year-old woman underwent a rightsided mastectomy for breast cancer. She subsequently presented to our clinic in 2003 with a history of severe neuropathic pain in the distribution of T5, T6, and T7 dermatomes. Investigations excluded a new primary site of carcinoma, bony metastases, infective, or other co-morbidities to explain this new pain. The pain was refractory to both conventional medical and interventional therapies such as thoracic facet joint injections and intercostal nerve blocks. A trial of PNS using a Pajunk catheter (PAJUNK UK Medical Products Ltd., Prestwick, England, United Kingdom), positioned in the right thoracic paravertebral plexus was undertaken and this provided $60-70 \%$ pain relief. Subsequently, under local anesthesia and fluoroscopic guidance, in a minimally invasive procedure, a quadpolar lead (Medtronic, Minneapolis, Minnesota) was positioned to lie at the T6 level. The electrode was then tunnelled to an incision made at the ipsilateral gluteal area and connected to an implantable pulse generator (IPG) (Medtronic, Minneapolis, Minnesota) inserted into a subcutaneous pocket in the gluteal area. The full implant provided $100 \%$ pain relief for 4 years using low frequency (10 $\mathrm{Hz}$ ), low amplitude (2 $\mathrm{mA}$ ) stimulation with a pulse width of 400 usec (Fig. 1).

In 2006 the patient fell while on vacation and sustained multiple left-sided rib fractures at T8, T9 and T10. She returned to our clinic complaining of severe hypersensitivity in the corresponding dermatomal area that significantly limited her daily activities. Visual analogue pain score (VAS) on movement was 8/10. Despite pharmacological therapy which included acetaminophen, non-steroidal anti-inflammatory drugs (NSAIDs), gabapentin, and amitriptyline, in combination with multiple level intercostal nerve blocks, and intercostal nerve pulsed radiofrequency, the patient continued to experience severe neuropathic pain. Notably, the patient remained pain free on the contralateral side where the thoracic paravertebral plexus remained in position.

PNS of the left thoracic paravertebral plexus was undertaken and following a successful trial with a
Pajunk catheter (PAJUNK UK Medical Products Ltd., Prestwick, England, United Kingdom), the patient proceeded to a full implantation in 2007 when a quadruple electrode (Medtronic, Minneapolis, Minnesota) was positioned to lie at the T9 level in order to capture the painful area (Fig. 2). The implantable power generator (IPG) was replaced with the synergy model (Medtronic, Minneapolis, Minnesota) at the same time. Low frequency $(10 \mathrm{~Hz})$, low amplitude $(2 \mathrm{~mA})$ stimulation targeted at the epicenter of the painful area produced effective and reproducible pain relief with a sustained VAS score 2/10 on movement. Unfortunately, within a year the left-sided pain returned (VAS > 8/10) and a lead malfunction secondary to a lead fracture was identified as the cause. Exploration and revision of the faulty lead was undertaken in 2008 and while this was complicated by the post-operative development, a small left-sided pneumothorax was identified on routine chest x-ray; it was determined clinically insignificant and resolved spontaneously. The patient has had functional targeted field stimulation in place for over 7 years that has provided an improved quality of life.

\section{Case 2}

A 65-year-old man presented with an 8-year history of low back and thoracic pain following a traffic accident in which he sustained fractures at T4, T5, T6, and T7 vertebrae. Co-morbidities included well-controlled Type II diabetes mellitus (glucose range 6.0 - 10.0) and a raised body mass index $\left(35.5 \mathrm{~kg} / \mathrm{m}^{2}\right)$. Despite several medications which included oral opioids, acetaminophen, non-steroidal anti-inflammatory drugs (NSAIDs), gabapentin, amitriptyline and ligocaine anesthetic transdermal patches, he continued to suffer a constant, dull aching pain that would keep him awake at night. Pain intensity (VAS) was reported as $8 / 10$ on movement. It was common for him to have severe episodes of pain which could last hours to days; he required hospitalization and intravenous morphine to manage the pain twice in a 6 month period. Intercostal nerve blocks with steroid and local anesthetic and pulsed radiofrequency intercostal denervation were either short-lived or ineffective. A PNS trial using Pajunk catheter placement (PAJUNK UK Medical Products Ltd., Prestwick, England, United Kingdom), reduced the pain intensity by $>70 \%$; full implantation was undertaken in 2000 when a quadpolar lead (Medtronic, Minneapolis, Minnesota) was positioned to lie at the T7 level using fluoroscopic guidance. The electrode was then tunnelled to an incision made at the ipsilateral gluteal area and connected to 

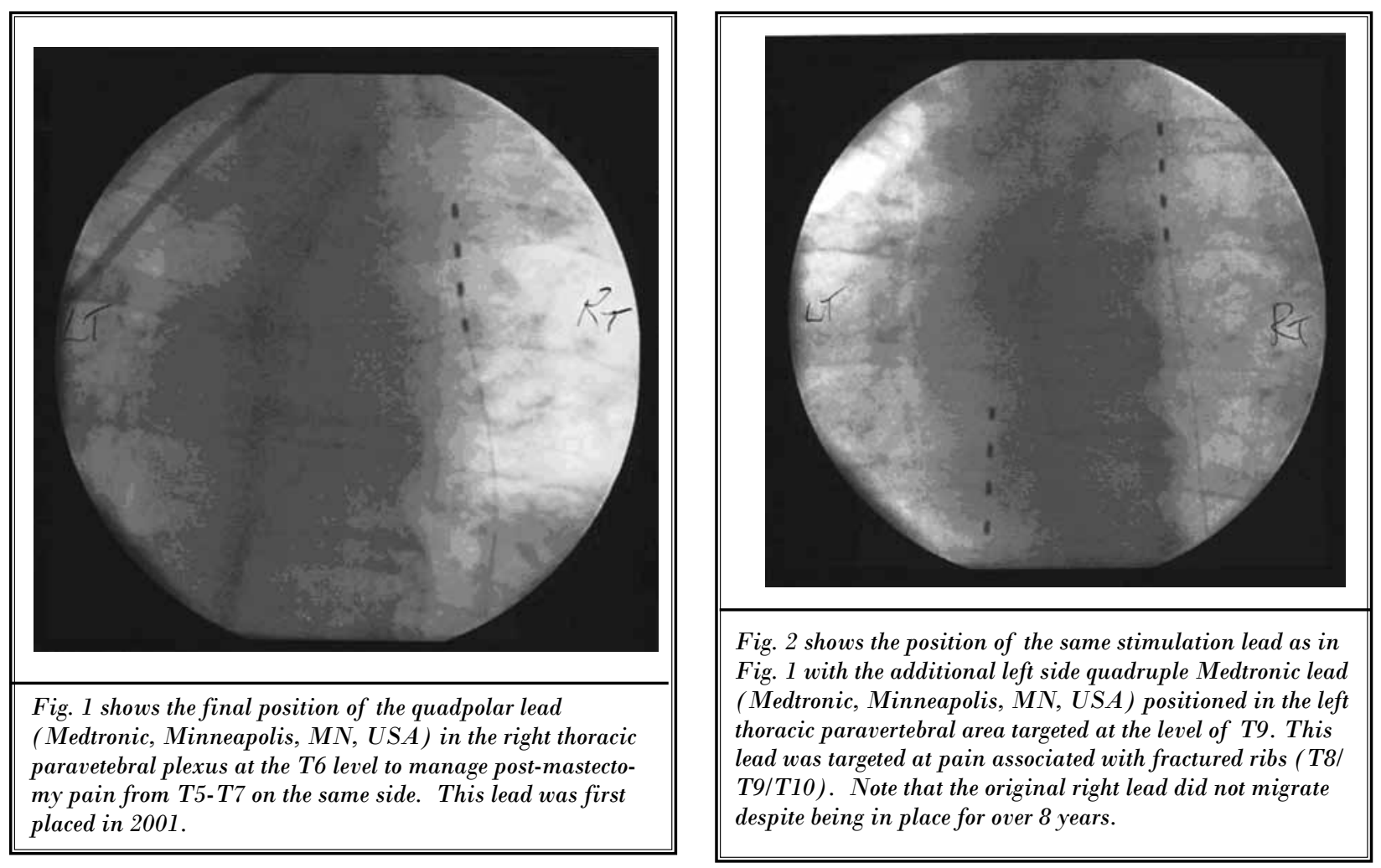

an implantable pulse generator (Medtronic, Minneapolis, Minnesota) inserted into a subcutaneous pocket in the gluteal area. The VAS score decreased to 2/10 with improved function and a gradual decrease in opioid consumption in the months that followed.

The patient remained comfortable for over 6 years, but in an effort to improve the coverage he returned for elective lead revision in 2006. During the procedure a pneumothorax was suspected when he complained of a sudden sharp chest pain, dyspnoea, and developed a tachycardia but otherwise remained hemodynamically stable. The procedure was abandoned, a chest drain was inserted, and it remained in situ for 36 hours, after which it was removed uneventfully. There was no radiological evidence of a pneumothorax at any point. A month later a new Medtronic Quad electrode (Medtronic, Minneapolis, Minnesota) was re-implanted without any complications. It was positioned at the level of T8-T9 in the paravertebral gutter. Low frequency stimulation $(10 \mathrm{~Hz})$, low amplitude $(2 \mathrm{~mA})$ stimulation targeted at the epicenter of the painful area again produced effective and reproducible pain relief but with better coverage of the painful area. Presently this patient reports $60-80 \%$ pain relief and is satisfied with his pain management and his quality of life. He describes

his stimulation as "smooth and gentle." He is presently off all opioids and uses acetaminophen for rescue management. His diabetes remains well under control and he has reduced his BMI as his mobility improved.

\section{Discussion}

The concept of stimulation analgesia was initiated following the publication of the Gate Control Theory in 1965 (4-13). Since 2000 peripheral nerve stimulation has regained popularity as a simple and effective neuromodulation technique for pain management (5-9). The use of thoracic paravertebral plexus stimulation as illustrated in the cases presented is unique for several reasons.

First, anatomically the thoracic paravertebral space offers an ideal target for successful stimulation. The thoracic paravertebral space (TPVS) is a wedge-shaped space (14) that lies on either side of the vertebral column (Fig. 1). The parietal pleura forms the anterolateral boundary, while the base is formed by the posterolateral aspect of the vertebral body, the intervertebral disc, the intervertebral foramen and its contents (15). The TPVS contains fatty tissue, within which lies the intercostal (spinal) nerve, the dorsal ramus, the intercostal 
vessels, the rami communicantes, and, anteriorly, the sympathetic chain (15). The spinal nerves in the TPVS are segmented into small bundles lying freely among the fat and devoid of a fascial sheath, which makes them exceptionally susceptible to local anesthetic block (16). The intercostal nerve and vessels are located behind the endothoracic fascia (17), while the sympathetic trunk is located anterior to it in the TPVS (18) (Fig. 1). This results in ipsilateral somatic and sympathetic nerve blockade in multiple contiguous thoracic dermatomes above and below. We believe that once positioned in the TPVS, the leads are less likely to migrate. As the first case illustrates, even in the event of significant trauma in the contralateral thoracic region, the original leads remained in position.

Second, the leads are sited using a percutaneous approach, thereby avoiding the central neuraxial system and also avoiding incising the hypersensitive peripheral skin to access the injured nerve. Percutaneous implantation of the stimulating electrode, via a stimulating needle to the peripheral nerves, is a relatively simple procedure and, as shown in our cases, is very effective. In our opinion, the implantation of the electrode via a percutaneous approach is both simpler to perform and is safer when compared to surgical implantation techniques, requiring incision and dissection to localize and expose the target painful nerve. The use of stimulating needles as an aid for identifying location prior to subsequent permanent electrode implantation has improved the precision and accuracy of the technique. In both cases presented, the patients were 61 and 65 years old respectively and the avoidance of a general anesthesia was thought to be in their best interest.

Third, only low frequency electrical stimulation, targeted at the epicenter of the painful area, is required to stimulate the thoracic paravertebral plexus and to provide effective and reproducible pain relief. The precise mode of action of the low-frequency stimulation on the paravertebral plexus has not been fully understood; however, a beneficial effect of lowfrequency stimulation has been documented in basic sciences and clinical applications. Low-frequency, lowvoltage electrical stimulation of the spinal cord in the epidural space has produced spinal hypalgesia and analgesia $(19,20)$. Application of a low-frequency stimulation to single nerves, plexuses, and targeted at a site of pain, mainly in neuropathic pain, has resulted in a substantial resolution of symptoms of varying duration (21-23). Permanent implantation in the case of targeted stimulation, single nerves, and plexuses has confirmed these findings (24). A conduction block of spinothalamic fibers by electrical field activation produced by the stimulating leads, has been suggested (25). However, this explanation seems less likely in view of the fact that the majority of these fibers are thin and have high activation thresholds. Paravertebral stimulation can possibly be explained by the "gate-control" theory of pain (26). Low frequency stimulation also has the added advantage of prolonging the battery life of the IPG.

While these cases describe a different approach to a clinically difficult dilemma, they were both notable for being complicated by the development of a pneumothorax, one of which required insertion of a chest drain. Based on published data, it is difficult to quote the true complication rate of thoracic paravertebral block associated with single or multiple injections, but it appears to be relatively low, ranging between 2.6$5 \%$ (1). The type and rate of complications prospectively reported after paravertebral (both thoracic and lumbar) injection blocks in 367 patients (319 adults, 48 children) showed the following frequency: vascular puncture, 3.8\%; hypotension, $4.6 \%$; pleural puncture, $1.1 \%$; and pneumothorax, $0.5 \%$ (27). We had no reason to expect either of the cases presented to be at a higher risk of this complication than normal, however, given the larger gauge needle used to position the stimulator leads, compared to the smaller gauge needles used for a traditional paravertebral block, a greater incidence of complications such as a pneumothorax might be expected. Clues that suggest pleural puncture are a definite pleural "pop" sensation, irritating cough, or sharp pain in the chest or shoulder during the procedure (28). Air is not aspirated unless the lung is inadvertently punctured or air enters the pleural cavity via the needle during removal of the stylet. This may explain the complication we report. While it is routine protocol to perform post procedure chest $x$-rays, these may or may not identify the complication. Advanced radiological intervention using interpleural injection (contrast) would be seen to move with respiration (28); it does not define any specific anatomical plane, rapidly disperses, and spreads to the diaphragmatic angle or horizontal fissure (28). A unique case of clicking pneumothorax is also described. This clinical entity is seen most commonly with small left apical pneumothorax and is characterized by the "Hamman sign," a clicking, bubbling, or crunching noise heard on auscultation near the apex of the heart in certain postures. Perhaps the use of realtime fluoroscopy or ultrasound monitoring to consider the needle position in relation to the pleura could be 
used to reduce the incidence; the development of suitable blunt needles is needed to improve patient safety. Ultimately, clinical awareness may provide the best indicator of this complication and ensure patient safety with early intervention.

The recent successful neurostimulation of more superficial peripheral nerves, such as those arising from the dorsal thoracic rami (9), should also be considered as a possible alternative approach to managing cases similar to those presented, especially with the reduced risk of complications.

Limitations of this evaluation include report of 2 cases which is considered as the lowest level of evidence (29-36) which may result in excessive utilization of interventional techniques (35-39), lack of description of other modalities of treatments including sympathetic blocks, intercostal nerve blocks, and epidural injec- tions which have been frequently utilized successfully in managing neuropathic pain apart from spinal pain (40-48).

\section{Conclusion}

Peripheral nerve stimulation of the thoracic paravertebral plexus with the placement of a percutaneously sited electrode offers a new and novel mode of managing refractory thoracic neuropathic pain. The 2 cases presented demonstrate the effectiveness of this intervention in the long-term management of this clinical dilemma. However, despite the simplicity, it is a procedure with inherent risk and one that must not be taken lightly. In the future a randomized controlled trial needs to be completed to assess the usefulness of this procedure and establish risk analysis.

\section{References}

1. Coveney E, Weltz CR, Greengrass R, Iglehart JD, Leight GS, Steele SM, Lyerly HK. Use of paravertebral block anesthesia in the surgical management of breast cancer: Experience in 156 cases. Ann Surg 1998; 227:496-501.

2. Vogt, D. Stieger, S, Theurillat C, Curatolo $M$. Single-injection thoracic paravertebral block for postoperative pain treatment after thoracoscopic surgery. $\mathrm{Br}$ J Anaesth 2005; 95 :816-821.

3. Kirvela $\mathrm{O}$, Antila $\mathrm{H}$. Thoracic paravertebral block in chronic postoperative pain. Reg Anesth 1992; 17:348-350.

4. Meizack K, Wall PD. Pain mechanism: A new theory. Science 1965: 150:971-979.

5. Lowry AM, Simopoulos TT. Spinal cord stimulation for the treatment of chronic knee pain following total knee replacement. Pain Physician 2010; 13:251-256.

6. McJunkin TL, Wuollet AL, Lynch PJ. Sacral nerve stimulation as a treatment modality for intractable neuropathic testicular pain. Pain Physician 2009; 12:991995.

7. Narouze SN, Zakari A, Vydyanathan A. Ultrasound-guided placement of a permanent percutaneous femoral nerve stimulator leads for the treatment of intractable femoral neuropathy. Pain Physician 2009; 12:E305-E308.

8. Trentman TL, Rosenfeld DM, Vargas BB, Schwedt TJ, Zimmerman RS, Dodick
DW. Greater occipital nerve stimulation via the Bion microstimulator: Implantation technique and stimulation parameters. Clinical trial: NCTo0205894. Pain Physician 2009; 12:621-628.

9. Falco FJE, Berger J, Vrable A, Onyewu O, Zhu J. Cross talk: A new method for peripheral nerve stimulation. An observational report with cadaveric verification. Pain Physician 2009; 12:965-983.

10. Goroszeniuk T, Kothari S. Subcutaneous targeted stimulation. In: Krames, Peckman, Rezai (eds). Neuromodulation. Elsevier, Oxford, UK, 2009.

11. Frey ME, Manchikanti L, Benyamin RM, Schultz DM, Smith HS, Cohen SP. Spinal cord stimulation for patients with failed back surgery syndrome: A systematic review. Pain Physician 2009; 12:379-397.

12. Manchikanti L, Boswell MV, Singh V, Benyamin RM, Fellows B, Abdi S, Buenaventura RM, Conn A, Datta S, Derby R, Falco FJE, Erhart S, Diwan S, Hayek SM, Helm S, Parr AT, Schultz DM, Smith HS, Wolfer LR, Hirsch JA. Comprehensive evidence-based guidelines for interventional techniques in the management of chronic spinal pain. Pain Physician 2009; 12:699-802.

13. Manchikanti L, Boswell MV, Datta S, Fellows B, Abdi S, Singh V, Benyamin RM, Falco FJE, Helm S, Hayek S, Smith HS Comprehensive review of therapeutic interventions in managing chronic spinal pain. Pain Physician 2009; 12:E123-E198.

14. Maclntosh R, Bryce-Smith R. Local Analgesia and Abdominal Surgery. Edinburgh, E\&S Livingstone, Edinburgh, UK, 1962, pp 26-32.

15. Im JG, Webb WR, Rosen A, Gamsu G. Costal pleura: Appearances at high-resolution CT. Radiology 1989; 171:125-131.

16. Nunn JF, Slavin G. Posterior intercostal nerve block for pain relief after cholecystectomy: Anatomical basis and efficacy. $\mathrm{Br}$ J Anaesth 1980; 52:253-26o.

17. Moore DC. Intercostal nerve block: Spread of india ink injected to the rib's costal groove. Br J Anaesth 1981; 53:325329.

18. Cheema SP, Ilsley D, Richardson J, Sabanathan S. A thermographic study of paravertebral analgesia. Anaesthesia 1995; 50:118-121.

19. Shimoji K, Kitamura H, Ikezono E. Spinal hypalgesia and analgesia by low frequency electrical stimulation in the epidural space. Anesthesiology 1974; 41:9194 .

20. Shimoji K, Matsuki M, Shimizu H. Lowfrequency, weak extradural stimulation in the management of intractable pain. Br J Anaesth 1977; 49:1081-1086.

21. Goroszeniuk T, Pratap N, Kothari S, Sanderson K. An algorithm for peripheral neuromodulation in neuropathic pain. Proceedings of 8th World Con- 
gress of INS and 11th Annual Meeting of NANS; December 2007; Acapulco, Mexico.

22. Paicius RM, Bernstein CA, Lempert-Cohen C. Peripheral nerve field stimulation in chronic abdominal pain. Pain Physician 2006; 9:261-266.

23. Petrovic Z, Goroszeniuk T, Kothari S. Percutaneous lumbar plexus stimulation in the treatment of intractable pain. Reg Anesth Pain Med 2007; 32 (Suppl. 1):11.

24. Goroszeniuk T, Kothari S, Hamann W. Subcutaneous neuromodulating implant targeted at the site of pain. Reg Anesth Pain Med 2006; 31:168-171.

25. Meyerson A, Linderoth B. Mechanisms of spinal cord stimulation in neuropathic pain. Neurol Res 2000; 22:285-292.

26. Stanton-Hicks M, Salamon J. Stimulation of central and peripheral nervous system for the control of pain. J Clin Neurophysiol 1997; 14:46-62.

27. Purcell-jones G, Justins DM. Postoperative paravertebral blocks for thoracic surgery (letter). Br J Anaesth 1988; 61:369-370

28. Purcell-Jones G, Pither CE, Justins DM. Paravertebral somatic nerve block: A clinical, radiographic, and computed tomographic study in chronic pain patients. Anesth Analg 1989; 68:32-39

29. Manchikanti L, Singh V, Smith HS, Hirsch JA. Evidence-based medicine, systematic reviews, and guidelines in interventional pain management: Part 4: Observational studies. Pain Physician 2009; 12:73-108.

30. Manchikanti L, Benyamin RM, Helm S, Hirsch JA. Evidence-based medicine, systematic reviews, and guidelines in interventional pain management: Part 3: Systematic reviews and meta-analysis of randomized trials. Pain Physician 2009; 12:35-72.

31. Manchikanti L, Hirsch JA, Smith HS. Evidence-based medicine, systematic reviews, and guidelines in interventional pain management: Part 2: Randomized controlled trials. Pain Physician 2008; 11:717-773.

32. Manchikanti L, Falco FJE, Boswell MV, Hirsch JA. Facts, fallacies, and politics of comparative effectiveness research: Part 1. Basic considerations. Pain Physician 2010; 13:E23-E54.

33. Manchikanti L, Falco FJE, Boswell MV, Hirsch JA. Facts, fallacies, and politics of comparative effectiveness research: Part 2. Implications for interventional pain management. Pain Physician 2010; 13:E55-E79.

34. Manchikanti L, Datta S, Gupta S, Munglani R, Bryce DA, Ward SP, Benyamin RM, Sharma ML, Helm II S, Fellows B, Hirsch JA. A critical review of the American Pain Society clinical practice guidelines for interventional techniques: Part 2. Therapeutic interventions. Pain Physician 2010; 13:E215-E264.

35. Benyamin RM, Datta S, Falco FJE. A perfect storm in interventional pain management: Regulated, but unbalanced. Pain Physician 2010; 13:109-116.

36. Manchikanti L, Singh V, Boswell MV. Interventional pain management at crossroads: The perfect storm brewing for a new decade of challenges. Pain Physician 2010; 13:E111-E140.

37. Manchikanti L, Singh V, Pampati V, Smith HS, Hirsch JA. Analysis of growth of interventional techniques in managing chronic pain in Medicare population: A 10-year evaluation from 1997 to 2006. Pain Physician 2009; 12:9-34.

38. Manchikanti L, Pampati V, Singh V, Boswell MV, Smith HS, Hirsch JA. Explosive growth of facet joint interventions in the Medicare population in the United States: A comparative evaluation of 1997, 2002, and 2006 data. BMC Health Serv Res 2010; 10:84.

39. Manchikanti L, Pampati V, Boswell MV, Smith HS, Hirsch JA. Analysis of the growth of epidural injections and costs in the Medicare population: A comparative evaluation of 1997, 2002, and 2006 data. Pain Physician 2010; 13:199-212.

40. Smith HS, Burton AW, Cheng J, Nguyen, Chopra P. Intercostal nerve blocks In: Manchikanti L, Singh V. (eds). Interventional Techniques in Chronic Non-Spinal Pain. ASIPP Publishing, Paducah, KY 2009. pp. 281-290.

41. Manchikanti L, Cash KA, McManus CD, Pampati V, Benyamin RM. A preliminary report of a randomized double-blind, active controlled trial of fluoroscopic thoracic interlaminar epidural injections in managing chronic thoracic pain. Pain Physician 2010; 13:E357-E369.

42. Manchikanti L, Cash KA, Pampati V, Wargo BW, Malla Y. Cervical epidural injections in chronic discogenic neck pain without disc herniation or radiculitis: Preliminary results of a randomized, double-blind, controlled trial. Pain Physician 2010; 13:E265-E278.

43. Manchikanti L, Cash KA, Pampati V, Wargo BW, Malla Y. The effectiveness of fluoroscopic cervical interlaminar epidural injections in managing chronic cervical disc herniation and radiculitis: Preliminary results of a randomized, double-blind, controlled trial. Pain Physician 2010; 13:223-236.

44. Manchikanti L, Singh V, Falco FJE, Cash KA, Pampati V. Evaluation of the effectiveness of lumbar interlaminar epidural injections in managing chronic pain of lumbar disc herniation or radiculitis: A randomized, double-blind, controlled trial. Pain Physician 2010; 13:343-355.

45. Manchikanti L, Cash KA, McManus CD, Pampati V, Benyamin R. Preliminary results of a randomized, double-blind, controlled trial of fluoroscopic lumbar interlaminar epidural injections in managing chronic lumbar discogenic pain without disc herniation or radiculitis. Pain Physician 2010; 13:E279-E292.

46. Manchikanti L, Singh V, Cash KA, Pampati $V$, Datta S. Management of pain of post lumbar surgery syndrome: Oneyear results of a randomized, doubleblind, active controlled trial of fluoroscopic caudal epidural injections. Pain Physician 2010; 13:509-521.

47. Parr AT, Diwan S, Abdi S. Lumbar interlaminar epidural injections in managing chronic low back and lower extremity pain: A systematic review. Pain Physician 2009; 12:163-188.

48. Benyamin RM, Singh V, Parr AT, Conn A, Diwan S, Abdi S. Systematic review of the effectiveness of cervical epidurals in the management of chronic neck pain. Pain Physician 2009; 12:137-157. 